$\begin{array}{ll} & \text { Etnográfica } \\ \text { etnográfica } & \text { Revista do Centro em Rede de Investigação em }\end{array}$

Antropologia

vol. 17 (2) | 2013

Vol. $17(2)$

\title{
Sobre o lugar e os usos das imagens na antropologia: notas críticas em tempos de audiovisualização do mundo
}

About the significance and the uses of images in anthropology: critical notes in times of the audio-visualization of the world

\section{Humberto Martins}

\section{(2) OpenEdition}

\section{Journals}

\section{Edição electrónica}

URL: https://journals.openedition.org/etnografica/3168

DOI: 10.4000/etnografica.3168

ISSN: 2182-2891

\section{Editora}

Centro em Rede de Investigação em Antropologia

\section{Edição impressa}

Data de publição: 1 junho 2013

Paginação: 395-419

ISSN: 0873-6561

\section{Refêrencia eletrónica}

Humberto Martins, «Sobre o lugar e os usos das imagens na antropologia: notas críticas em tempos de audiovisualização do mundo», Etnográfica [Online], vol. 17 (2) | 2013, posto online no dia 20 junho 2013, consultado o 09 fevereiro 2022. URL: http://journals.openedition.org/etnografica/3168 ; DOI: https://doi.org/10.4000/etnografica.3168

\section{(c) (7) \&}

Etnográfica is licensed under a Creative Commons Attribution-NonCommercial 4.0 International License. 


\section{Sobre o lugar e os usos das imagens na antropologia: notas críticas em tempos de audiovisualização do mundo}

\section{Humberto Martins}

Neste artigo discuto o lugar e os usos das imagens na antropologia social. Identificando insuficiências nos diálogos entre antropólogos visuais e não visuais, apelo à intensificação do uso das imagens (audiovisuais) como ferramentas de investigação (metodologia) e de análise (teoria) na antropologia. Esta reivindicação faz reconhecer não só o facto de os objetos (sujeitos) de estudo da antropologia serem hoje mais visíveis e visualizáveis na forma como podem, devem e querem ser abordados (ligando a correntes teóricas, epistemológicas, políticas e ideológicas emergentes na disciplina), mas também uma atitude mais reflexiva da parte dos antropólogos nas suas investigações, servindo as imagens como reveladoras dos encontros entre observados e observadores e dos processos de construção negociada, continuada e circunstancial do conhecimento e das representações produzidas durante e após o trabalho de campo. O argumento tem em atenção, por um lado, a crescente acessibilidade e difusão dos meios e produtos audiovisuais e, por outro, a necessidade do seu maior reconhecimento para efeitos dos currículos académico-científicos dos antropólogos.

PALAVRAS-CHAVE: antropologia visual, etnografia, reflexividade, imagens.

About the significance and the uses of images in anthropology: critical notes in times of the audio-visualization of the world - In this text I discuss the significance and the uses of images in social anthropology. By identifying insufficiencies in the dialogues between visual and non-visual anthropologists, I claim for an intensification of the use of images (audio-visual) in anthropology, both as a research (methodology) and as an analysis tool (theory). This claiming acknowledges not only the fact that anthropology's subjects are today more visible and visualisable in the way they can, must and want to be studied (connecting to emergent theoretical, epistemological, political and ideological frameworks in the discipline) but also a more reflexive attitude of the anthropologists in their research processes; accordingly, images may serve to reveal encounters between observed and observers as well as ongoing, negotiated and circumstantial construction processes of knowledge and representations both in the field and post-field moments. The overall argument considers not only the increasing accessibility and diffusion of audio-visual products and means but also its greater recognition regarding the anthropologists' academic and scientific curricula.

KEYWORDS: visual anthropology, images, ethnography, reflexivity.

MARTINS, Humberto (humbmsm@yahoo.com) - UTAD; Centro em Rede de Investigação em Antropologia (ISCTE - Instituto Universitário de Lisboa), Portugal. 


\begin{abstract}
"Will the new ethnographic films be subject to less marginalization and more acceptance from the mainstream of cultural anthropology as a serious means of anthropological expression, or will they remain merely an audiovisual aid to teaching?" (Durington e Ruby 201 1: 201).
\end{abstract}

\title{
(LONGO) IMPULSO PARA UMA REFLEXÃO
}

A ideia de escrever este artigo resulta de um certo desapontamento pessoal com o facto de não ver partilhado com maior frequência e intensidade, entre antropólogos visuais e não visuais, o espaço de produção, mostra, utilização e reflexão acerca de produtos audiovisuais. Em concreto, tenho a perceção de que quem trabalha com imagens na antropologia está à parte dos restantes antropólogos através de processos que, em bom rigor, são de auto e heteroexclusão e com visíveis manifestações nos diferentes encontros científicos que vão sendo promovidos - pela European Association of Social Anthropologists (EASA), pela Société Internationale d'Ethnologie et de Folklore (SIEF), pela Associação Portuguesa de Antropologia (APA) -, nos quais a produção audiovisual é relegada para uma marginalidade teórico-epistemológica. Parece-me, por outro lado, que a divisão disciplinar (não visual - visual), menos imposta do que assumida, ajuda a manter num certo nojo uma reflexão crítica mais profunda e alargada (a toda a antropologia) sobre a forma como as imagens são tratadas nas pesquisas antropológicas e recebidas ou acedidas nas mais variadas formas da sua exibição pública e, em particular, nos encontros científicos. Diria, portanto, que o audiovisual mantém na antropologia um estatuto de marginalidade duplamente produzido e reproduzido por antropólogos visuais e não visuais.

De facto, os antropólogos visuais continuam (mais) a falar e a mostrar produções entre si e pouco contacto é estabelecido, em termos do que se escreve sobre teoria, metodologia e epistemologia, com os restantes antropólogos. Neste particular, alguns factos parecem evidentes, fazendo a apreciação do que observo nos referidos encontros científicos portugueses e europeus e apesar de as mostras de filme (etnográfico ou documentário) e as exposições (fotografia e instalações audiovisuais) integrarem, cada vez mais, os seus programas: (1) as sessões de mostra de filme decorrem com a presença maioritária ou exclusiva dos antropólogos visuais e/ou dos produtores e realizadores, que, muitas vezes, não têm formação antropológica (uma tendência muito estimulada pelos próprios antropólogos visuais); (2) os debates sobre os filmes têm poucas ou nenhumas ligações com debates teóricos que se vão produzindo na ciência antropológica mais vasta; (3) os painéis organizados sobre temas preferencialmente "visuais" são frequentados apenas por antropólogos visuais; (4) poucas ou nenhumas referências são feitas nos painéis "não visuais" a filmes, fotografia e produtos audiovisuais mais em geral; (5) os produtos audiovisuais, nomeadamente filmes, não são convocados com uma maior 
frequênciaparaos diálogos metodológicos, teóricoseepistemológicospromovidos pelos antropólogos não visuais nos seus textos e comunicações, mesmo aqueles que tratam de objetos ou temas com produção audiovisual relacionada; (6) poucos painéis promovem, de facto, um encontro de abordagens visuais e não visuais; (7) raramente a abertura destes encontros ou de sessões plenárias é feita com a exibição de um produto audiovisual; (8) o reconhecimento curricular (científico e académico) dos produtos audiovisuais não está instituído a um mesmo nível do da produção textual.

Dito disto, importa referir que este texto não se assume como um manifesto pró-visual; pelo contrário, o objetivo é o de estimular diálogos entre antropólogos, colocando a antropologia visual em lugares mais centrais nos debates teóricos, metodológicos e epistemológicos da antropologia social em Portugal. ${ }^{1}$ Também não pretendo traçar a história da antropologia visual (portuguesa) nem tampouco reivindicar uma centralidade extraordinária para a mesma. ${ }^{2}$ Apesar de investigar com imagens - fotografia e filme etnográfico (Martins 2005) -, não me assumo como antropólogo visual. A minha perspetiva é, também, a de que a distinção entre antropólogos visuais e não visuais serve apenas para efeitos de argumento textual. Considero que os antropólogos fazem antropologia e que as especializações não nos devem fazer diferenciar subcategorias profissionais ou académicas (e.g. antropólogo visual ou antropólogo político), embora reconheça que a antropologia visual dialoga com outros saberes e afazeres (as artes, em geral, e o cinema e a fotografia, em particular - Edwards 2011 ; Schneider 2011; Gray 2010; Griffiths 2002; Okely 2001; Grimshaw 1997, 2001b) e que, também por isso, em muitos momentos públicos de divulgação e discussão dos seus produtos, os interlocutores em presença não são (nem teriam de ser) maioritariamente antropólogos (Banks e Ruby 201 1). Esta constatação não significa que os produtos audiovisuais, mesmo sem intencionalidade científica explícita e/ou explicitada, não sirvam à antropologia e aos antropólogos.

No meu trabalho, por exemplo, utilizo imagens sempre que considero necessário aceder a determinados aspetos da realidade social que me escapam nas formas de pesquisar não visuais e nas representações criadas via texto escrito, ou para propor diferentes perspetivas de uma mesma realidade (Ginsburg 2011 ; Martins 2005); invoco, neste particular, não só as formas hápticas de

I Falarei quase sempre e só da antropologia social (ou cultural), reconhecendo que existem linhas de discussão específicas sobre o papel das imagens no âmbito de uma antropologia física e biológica e da própria arqueologia. Sobre a antropologia cultural haveria também que reconhecer particularidades históricas e disciplinares, extensíveis aos usos das imagens, mas que extravasam os propósitos deste texto. Ver, por exemplo, Griffiths (2002).

2 Vários autores vêm reconhecendo, efetivamente, a existência de outras histórias do visual na antropologia não maioritariamente anglófona ou francófona (Edwards 2011; Banks e Ruby 2011; Durington e Ruby 2011; Davey 2010), que, como no caso português, ainda estão por contar ou conhecer. Esse reconhecimento aclarará, seguramente, várias histórias regionais e nacionais da própria antropologia social. 
conhecimento (Grimshaw 2005), que no âmbito de uma antropologia ambiental (e.g. Lee e Ingold 2006; Pink 2007a) e de uma antropologia da experiência e dos sentidos (Pink 2006; Grimshaw e Ravetz 2005) têm sido valorizadas, mas, também, o que Farnell (2011) define como uma perspetiva agencial do movimento humano - ou seja, uma antropologia que enfatiza produções espacializadas e corporalizadas de conhecimento, compostas de inúmeras interações, movimentos, gestos e olhares, que através da descrição escrita via texto não se conseguem transmitir. Farnell fala de uma segunda revolução somática para sublinhar a ideia de que "the way human agency works is in terms of the signifying enactments of moving" (2011: 154); assim, a melhor forma de captar o movimento (motion) de uma "moving person" - e de epistemologicamente manter a sua integridade - será através das imagens e dos sons (motion pictures), garantindo, assim, menor perda de informação no processo de tradução (transcrição) do observado in situ.

Este conjunto de notas críticas ganhou um forte impulso com a mostra de filme etnográfico que teve lugar no congresso da SIEF realizado em Lisboa em abril de 2011 e do qual fui um dos programadores, em particular com a exibição do documentário O Compasso (Regina Guimarães e Saguenail, 2008), realizado no âmbito de uma investigação sociológica sobre Fonte Arcada (coordenada por José Madureira Pinto e João Queirós da Universidade do Porto). O filme, feito num registo wisemaniano de longa duração e produzido como complemento à investigação não visual sobre transformações em meio rural, revela aspetos que escapam ao texto escrito e nos quais se inclui a própria investigação enquanto processo interativo e relacional que envolve diferentes atores sociais (personagens em filme) - sociólogos, tarefeiros e sujeitos estudados. A câmara ajudou, de facto, a "abrir" a investigação, tornando-a mais pública (percetível), não só, e em particular, para os sujeitos da investigação (Pinto 2010), mas, também, para os próprios investigadores/realizadores.

Em suma, considerando, por um lado, o privilégio do sentido da visão na pesquisa antropológica (Herzfeld 201 l; Grimshaw 200lb; Fabian 1983) e, $^{3}$ por outro, o predomínio da palavra escrita na transmissão do conhecimento e

3 Têm sido, em grande medida, os antropólogos visuais a apontar o dedo ao "ocularcentrismo" predominante na disciplina (e.g. Grimshaw 200lb). A crítica ao "despotismo do olho" (sobre os outros sentidos nos processos de pesquisa) levou a que, por exemplo e mais recentemente, seja valorizada a importância do som e da música nos documentários e filmes etnográficos (Henley 2004). Para Henley (2004), importa considerar num filme etnográfico as diferentes sínteses e composições de sons e imagens gravadas e/ou editadas para aceder integralmente às dimensões culturais que se pretende mostrar. Por outro lado, Okely (2001) identifica visão e visualismo como um compósito alargado que engloba todos os sentidos e um envolvimento experiencial subjetivo, ao mesmo tempo que critica a associação entre visão e vigilância que está na base do argumento de Fabian (1983) - um ponto que Herzfeld (2011) acolhe, no sentido de pôr em causa a divisão entre visual e verbal. Toda a antropologia, para este autor, tem por objetivo registar (to record) dados etnográficos, independentemente dos suportes e tipos de registo. 
na produção de representações sobre o "outro" (Herzfeld 201 1; Mead 1975), ${ }^{4}$ importa retomar alguns dos clássicos questionamentos da antropologia visual na sua relação com a antropologia. O que fazer com o visual na antropologia (MacDougall 1997)? E qual o lugar do visual na antropologia social, reconhecendo que existe uma antropologia visual (e do visual) que tem uma vida própria (Banks e Ruby 201 l; Ruby 2005)? Como e porquê usamos as imagens na antropologia? Servirão as imagens por si só como interpretações alternativas da realidade social? Reabrindo, assim, o debate em torno das virtudes epistemológicas do visual, conseguimos aceder a, e mostrar, aspetos da realidade que, de outra forma, nos escapariam? Ou seja, trazem as imagens novos conhecimentos sobre a realidade social? Ou servem as imagens apenas para confirmar ou ilustrar um argumento escrito e, no limite, a sua função operatória do ponto de vista metodológico-epistemológico é residual, nada acrescentando de novo em termos de representação e/ou conhecimento? As perguntas, embora não originais (Campos 201 1; Banks e Ruby 2011 ; Grimshaw 2005; Griffiths 2002; MacDougall 1997; Mead 1975), são atuais, em virtude do que me parece ser a manutenção de um afastamento intencional entre quem não trabalha preferencialmente com imagens e quem o faz - incluindo profissionais e amadores que realizam produtos audiovisuais com potencial etnográfico (Edwards 201 l; Durington e Ruby 201 1; Pink 2001a, 2001b).

\section{AFASTAMENTOS E APROXIMAÇÕES \\ (OU O LUGAR DO VISUAL NA ANTROPOLOGIA)}

A história da antropologia visual, por proximidade maior ou menor, é a da própria antropologia (Edwards 2011; Grimshaw 200lb, 2005; Griffiths 2002), não obstante tendências e trajetos terem divergido em determinadas fases ou períodos da mesma e se reconhecer a institucionalização da antropologia visual como projeto consolidado apenas a partir da Segunda Guerra Mundial, com impulso decisivo a partir dos anos 70 do século XX (Banks e Ruby 2011). De facto, não podemos afirmar que a antropologia tenha depreciado o visual na sua história; muito pelo contrário. Neste ponto importa ativar uma distinção entre os denominados campos da antropologia. Se a imagem (fixa e em movimento, nos seus mais variados desenvolvimentos técnicos) teve um lugar de destaque como ferramenta de pesquisa e como prova (evidência) na antropologia físico-antropométrica da segunda metade do século XIX, já o mesmo não se pode dizer do período de "sociologização" teórico-epistemológica da disciplina, com os paradigmas dominantes da primeira metade do século XX. $\mathrm{Na}$ primeira fase, a história da imagem, e em particular da fotografia, está 
recheada de contributos vários (Griffiths 2002). Os projetos de fotografia antropométrica, nos quais pode ser incluída a cronofotografia de Étienne-Jules Marey (Griffiths 2002), com a obsessão positivista-objetivista de medições, classificações e comparações entre corpos, especímenes de raças ou grupos culturais, tiveram um forte impulso com as emergentes técnicas desse período - o que Pinney, classificando o entusiasmo e fé no signo (evidência) visual do período evolucionista da antropologia, denominou como "a verdade do cientismo fotográfico" (cit. em Griffiths 2002: 99). Esse tipo de abordagem seria criticado no virar do século por fotógrafos de um estilo mais naturalista, que identificavam a falta de contexto - da cultura viva que estaria ausente das fotografias de corpos nus em pose segundo instrumentos de medição no estilo antropométrico (Griffiths 2002).

Contudo, apesar de a antropologia social, em especial com a afirmação dos paradigmas teóricos funcionalistas e estruturalistas (sociológico-analíticos), ter privilegiado o invisível relativamente ao visível das culturas, dando ênfase em largo período da primeira metade do século XX a conceitos abstratos (não visualizáveis), como os de função, estrutura, organização social, que reivindicavam mais o lápis e a palavra escrita do que a câmara e a imagem (Wolbert 2000; Mead 1975; Temaner e Quinn 1975), a história da antropologia tem sido feita entre o verbal e o visual (Herzfeld 2011). Mesmo nas clássicas monografias fundadoras da antropologia sociológica moderna, autores como Malinowski ou Evans-Pritchard representaram visualmente o que conheceram, tendo produzido conjuntos volumosos de imagens - especialmente fotográficas (Edwards 2011; Morton 2005; Wolbert 2000).

Nesta história do visual na antropologia também não podemos esquecer o projeto de antropologia aplicada de Margaret Mead e Gregory Bateson no Bali (anos 30 do século passado), que conduziu à produção de vários filmes e fotografias (e.g. A Balinese Family) e do próprio "momento" fundador do moderno trabalho de campo antropológico com a "famosa" expedição ao Estreito de Torres no Pacífico, num projeto da Universidade de Cambridge liderado por Alfred Cort Haddon em 1898. Os filmes realizados pela equipa de Haddon são considerados pioneiros na história do filme etnográfico, surgindo apenas três anos depois das experimentações dos irmãos Lumière nas ruas de Paris e que, considerados pelo prisma de que filmam pessoas "reais", também podem ser vistos como filmes etnográficos (Durington e Ruby 201 1). Apesar de baseados numa reconstituição de práticas culturais - com encenação - e no âmbito de uma salvage anthropology atenta aos mundos em desaparecimento e aos aspetos materiais e folclóricos, os filmes e o projeto de Haddon são devedores de uma

5 Também são pioneiros, embora mais esquecidos nas histórias da antropologia (visual), os trabalhos fotográficos e fílmicos de Baldwin Spencer entre as comunidades aborígenes na Austrália e as tentativas de Haddon e de Spencer na captação do som (Griffiths 2002). 
antropologia de contacto e contexto - que tem em W.H. Rivers um dos seus principais intérpretes -, isto é, uma antropologia que, por um lado, queria ter acesso em primeira mão ao ponto de vista nativo tal como produzido em contexto (Grimshaw 200la e 200lb) e, por outro, não queria deixar de registar mundos humanos (naturais e culturais) em "eventual" extinção. Neste sentido, é interessante verificar como parece ser constante esta ideia de mundos em desaparecimento para uma antropologia que precisa de recorrer ao visual. Anos mais tarde (70-90 do século XX), a Granada Television (Reino Unido) em colaboração com o Departamento de Antropologia Social da Universidade de Manchester, levou a efeito um bem-sucedido projeto de filmes documentários de raiz etnográfica com o título Disappearing World/O Mundo em Extinção, com localizações de filmagem um pouco por todo o mundo (incluindo a Europa). Também a clássica crítica de Mead (1975) ao insuficiente uso de audiovisuais na antropologia fala da urgência em não deixar perder traços e elementos culturais e da responsabilidade dos antropólogos quanto ao seu registo por meios visuais.

$\mathrm{Na}$ antropologia portuguesa encontramos também muitos trabalhos que são complementados com recurso a imagens (fotografia ou vídeo). Algumas correntes, focadas em aspetos de cultura material, património coletivo e elementos folcloristas, têm feito um uso sistematizado das imagens (com uso da fotografia e/ou do filme). O trabalho realizado pela equipa de Jorge Dias no contexto do Centro de Estudos de Etnologia (que viria a estar na origem do Museu de Etnologia) é um bom exemplo. Em particular, em relação ao filme etnográfico em Portugal, Benjamim Pereira teve um papel muito ativo desde os anos 50 do século passado, com extensão ao trabalho colaborativo com a equipa do Institut für den Wissenschaftlichen Film, de Göttingen, nos anos 70 , que levou à produção de uma extensa (e intensiva) etnografia fílmica sobre tradições populares portuguesas. ${ }^{6}$

Entretanto, vários antropólogos portugueses têm realizado filmes etnográficos e documentários ou participado com aconselhamento científico em projetos fílmicos, revelando a sua disponibilidade para a utilização de meios e produtos audiovisuais no âmbito de pesquisas antropológicas. Também a fotografia é presença assídua nos trabalhos realizados, com exemplos que, por tão diversificados, não caberiam neste texto. Cito apenas dois. Na coleção Portugal de Perto das Publicações Dom Quixote, onde estão representadas etnografias marcantes feitas sobre Portugal, o trabalho de Joaquim Pais de Brito (1996) apresenta um interessante conjunto de fotografias (proposta seguida noutras obras da coleção) que vai além da mera ilustração. As fotografias assumem-se,

6 Ver, a este propósito, o volume 14 (1) de Etnográfica (2010), com secção dedicada ao trabalho e obra do autor. Sobre a sua filmografia, registos fotográficos e outras autorias e colaborações na produção de materiais audiovisuais, ver, no mesmo número, a recolha de Branca Moriés e Clara Saraiva (2010). 
com a ajuda das legendas (algumas muito descritivas), como um ensaio paralelo, permitindo-nos perceber de outra forma (mais sensorial) aspetos da organização da vida social local que o texto escrito não consegue passar. Recentemente, numa parceria do CRIA e da Câmara Municipal de Lisboa, Chiara Pussetti coorganizou com Vítor Barros a exposição multimédia "Woundscapes: Sofrimento, Criatividade e Vida Nua", que contou com colaborações antropoartísticas de vários antropólogos. ${ }^{7}$

Todavia, reparo que as imagens tendem a ser pouco utilizadas e/ou usadas sem que haja necessariamente uma reflexão (Edwards 2011; Martins 2011), servindo um propósito que considero pouco ambicioso de, por um lado e em termos da publicação de monografias antropológicas, mostrar os contextos e sujeitos investigados, o que tem como exemplo preferencial o da fotografia ilustrativa com ambição empírico-realista (Edwards 2011; Cornu 2010; Hammond 1998), isto é, são um registo que visa autenticar ou garantir determinada evidência objetiva de uma presença num terreno de estudo, de um contexto físico, performance e/ou de um sujeito observado; por outro lado, as imagens servem projetos pessoais ou coletivos paralelos, que se situam fora das academias e que intencionalmente procuram novas audiências ou mesmo novos formatos de comunicação. ${ }^{8}$ As imagens, nos dois casos, tendem a tornar-se residuais ou marginais face ao lugar central ocupado pelo texto escrito ou pelo discurso que privilegia as palavras ditas. Não existe uma equalização estatutária em termos de produção argumentativa, que poderia traduzir-se, em termos concretos, na utilização de mais imagens (filmes, fotografias, desenhos) nos artigos e apresentações orais, com maior exploração dos conteúdos interpretativos associados - num cruzamento mais profícuo de várias técnicas de pesquisa, teorias e epistemologias.

Edwards (2011) assinala que uma certa iconofobia vigente, não só na antropologia mas um pouco por todas as ciências sociais, deriva das virtudes polissémicas associadas às imagens e que podem, precisamente, fazer perigar a desejada objetividade de um certo modelo (positivista-racionalista) que nelas tem imperado. Para esta autora, a história da utilização da fotografia na antropologia (o seu foco principal de discussão) revela continuados "cuidados" delimitadores das eventuais fugas ao jugo da objetividade assente no valor indexical-realista da mesma. Através, por exemplo, do controlo físico dos objetos ou sujeitos filmados (com estilos associados, como o da "pose"), ou pelo recurso a legendas, vários autores (onde estão incluídas referências da antropologia como Malinowski ou Evans-Pritchard) tentam atingir mais ou

7 A exposição esteve patente no Museu da Cidade de Lisboa de 19 de Maio a 8 de Julho de 2012.

8 A fotografia, especialmente a digital, está hoje amplamente democratizada e tem um custo baixo, mesmo se comparado com o do vídeo digital. Retomando um argumento identificado nos escritos de antropologia visual (e.g. Rouch 1975), a utilização dos meios audiovisuais sempre esteve dependente do seu custo e acesso (Griffiths 2002). 
menos naturalisticamente uma representação objetiva da realidade (Edwards 2011). No entanto, Edwards aborda a impossibilidade ou falácia da câmara (registo) neutral, fazendo acionar o argumento da construção social e cultural do olhar; por um lado, não vemos todos a mesma coisa da mesma forma (Okely 2001) e, por outro, existe sempre um estilo ou escolha autoral - isto é, reconhece-se a impossibilidade de um não-estilo, desvelando, assim, o trabalho de seleção do fotógrafo/antropólogo.

\section{HÁ ANTROPOLOGIA SEM TEXTO?}

"Attitudes among anthropologists toward film have been anything but unified throughout the history of the discipline. This ambivalence $[\ldots]$ is the result of cinema's simultaneous appeal to scientific verisimilitude and visual spectacle" (Griffiths 2002: 312 ).

Vários são, de facto, os comentários depreciativos de antropólogos não visuais sobre a qualidade antropológica de alguns projetos audiovisuais e, em especial, a dos documentários. "Isso não é antropologia", ouço amiúde, particularmente fazendo referência à fraca ou inexistente contextualização histórica e teórica dos filmes (porque insuficiente em termos de trabalho de campo realizado), a que acresce uma suposta falta de estudo comparativo que pudesse, de alguma forma, aproximar-se do filme científico-analítico do género da série realizada por Mead e Bateson no Bali ou de The Ax Fight (Asch e Chagnon 1975). ${ }^{9}$ Esta é, aliás, uma questão que Stoller (1992) comenta detalhadamente em relação à apreciação que é feita no seio da antropologia à etnografia fílmica de Jean Rouch - muito menosprezada pela (eventual) insuficiência científica dos seus registos, numa crítica clara à não integralidade (contextual) e profundidade (teórica) dos mesmos.

Noutras vezes, a ênfase depreciativa é colocada na dimensão espetacular do registo imagético, como se o "outro" enquanto conceito referencial da antropologia fosse apresentado como demasiado exótico, numa espécie de manipulação (edição) da sua singularidade. Voltamos neste ponto não só à crítica feita à instabilidade semântica dos enunciados visuais e à dificuldade em assegurar uma garantia da representação feita sobre coletivos, na qual se inscreve o problema da contextualização e da perda de controlo do autor sobre a utilização das imagens, mas, sobretudo, a uma eventual superficialidade na abordagem que tem como limite a falta de tempo de estudo dedicado às pessoas representadas, isto é, a um trabalho de campo que supostamente não explora com profundidade suficiente a realidade estudada. Esta segunda apreciação negativa reconhece

9 The Ax Fight é, no entanto, reconhecido por outras virtudes e possibilidades hápticas (Asch, Marshall e Spier 1973). 
também uma questão epistemológica central, relacionada com os acessos preferenciais do conceito de cultura e a emergência do hermeneutic turn na antropologia da segunda metade do século XX. Ou seja, à cultura não se acederia por comportamentos, práticas ou através de elementos materiais, o que significaria uma quase impossibilidade epistemológica da sua representação visual.

Sobre este assunto, Grimshaw (200la e 200lb) fez semelhante reflexão para o Granada Centre for Visual Anthropology (GCVA) da Universidade de Manchester, constatando a crescente dificuldade de afirmação e prova da "antropologicidade" dos documentários produzidos pelos estudantes do MA in Visual Anthropology daquele centro, por razão não só dos objetos e sujeitos filmados, mas, igualmente, pelos próprios acessos metodológicos e fracas "pontes” teóricas com a antropologia mais em geral. Uma das críticas apontadas, e discutida por Grimshaw (200la e 200lb), sugeria que os filmes produzidos seriam cada vez menos etnográficos, seguindo convenções televisivas do género docusoap. Isto é, os filmes seguiriam indivíduos excêntricos do ponto de vista social, criando narrativas culturais sujeitas ao ritmo das exigências televisivas e não respeitando aquilo que Rouch (1975) designou por integralidade da realidade observada, com base num envolvimento demorado e sujeito a um processo de estranhamento, que, justamente, justifica a sua continuada descoberta. De certa forma, nesta formulação podemos ancorar a definição de filme etnográfico proposta no início dos anos 70 do século passado pelo realizador e antropólogo francês (Rouch 1975), que, ao contrário do que diziam alguns dos seus críticos, indiciava como necessária a prática de um trabalho de campo com observação participante do género malinowskiano. Mais tarde, é o próprio Rouch, no entanto, que, assumindo a ambição de uma generalização da prática (produção e receção) do filme etnográfico na antropologia, identifica alguns dos riscos de uma produção descontrolada:

"O nosso objetivo [Comité du Film Ethnographique] era de uma grande ambição: iniciar o diálogo entre o rigor científico e a arte cinematográfica. Mas, desde aí, o Filme Etnográfico tornou-se adulto e reconhecido no mundo inteiro sob o nome de Visual Anthropology-Antropologia Visual. Esta evolução foi possível graças à televisão [...] Mas hoje é essa mesma televisão que, ao introduzir uma imagem eletrónica efémera e, sobretudo, ao impor a criação de quadros rígidos de difusão (13', 26' ou 52'), se arrisca a pôr em questão as regras elementares da nossa disciplina” (Rouch 1995: 11).

Por outro lado, apesar de a antropologia visual ser uma disciplina per se desde meados dos anos 70 do século passado (Banks e Ruby 201 1; Hockings 1975; Mead 1975), de os registos visuais acompanharem toda a história da antropologia moderna (Grimshaw $200 \mathrm{lb}$; Griffiths 2002), e da sua crescente afirmação através da proliferação de cursos e escolas por todo o mundo, ela 


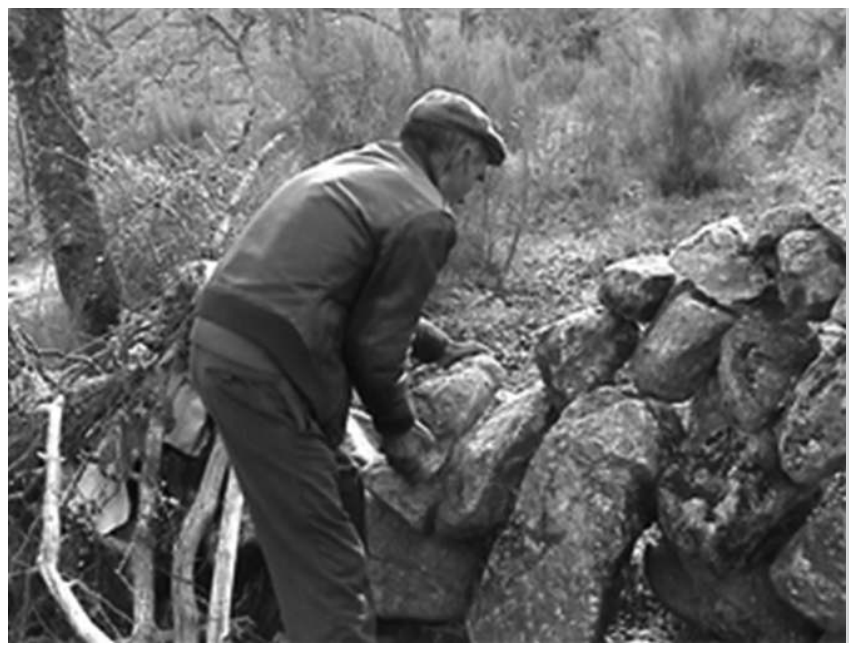

Figura 1

Zé da Paneira ceibando um lameiro para que o gado passe.

Fonte: Humberto Martins, do filme Fazendo (o) Tempo (2003).

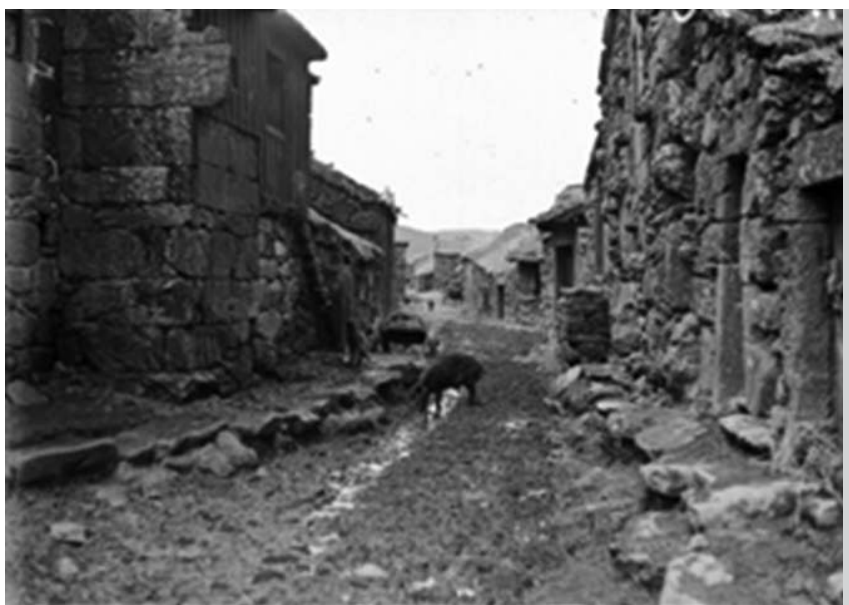

Figura 2

Rua de Padroso,

Montalegre (legenda original).

Fonte: Centro Português de Fotografia, Álbum António Ferro, 1933.

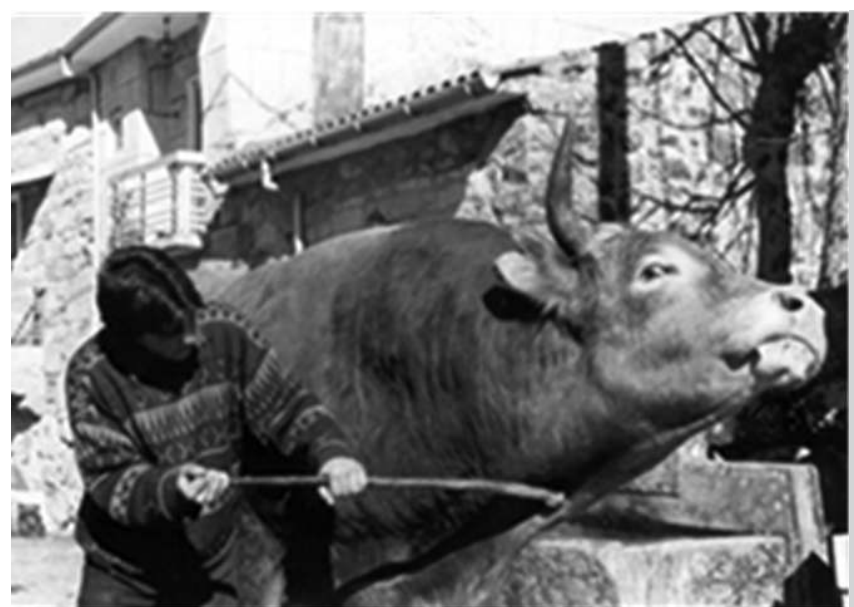

Figura 3

Rui do Giestas "coça”

o Rubio, tentando acalmá-lo.

Fonte: Humberto Martins (2001). 
não se define, ao contrário de outras "especializações" antropológicas, pela especificidade do seu objeto, como acontece, por exemplo, com a antropologia política ou a antropologia das religiões. Embora exista uma antropologia do visual (Ruby 2005; Ribeiro 2004) que analisa sistemas e culturas visuais e as imagens ou produções visuais enquanto geradoras de significados (Ribeiro 2004), a antropologia visual que tem predominado assenta numa base metodológica na qual o filme etnográfico ou o documentário têm lugar central (Ruby 2005). Ou seja, são feitos filmes sobre culturas, sociedades e indivíduos ou estudam-se culturas, sociedades e indivíduos através de filmes não necessariamente etnográficos na sua intenção original de produção, mas que concorrem com as abordagens textuais e analíticas sobre os mesmos objetos de estudo.

Quer isto dizer que a antropologia visual, apesar de várias reivindicações de novas explorações metodológicas, teóricas e epistemológicas (Ruby 2005; MacDougall 1995), se tem afirmado sobretudo através de trabalhos que devem muito às etnografias de base convencional, nomeadamente na criação de uma linearidade narrativa que pouco ajuda a revelar (desconstruir) as complexidades, incoerências ou inconstâncias da vida social; isto é, as etnografias visuais em formato fílmico ou fotográfico predominam e apresentam-se, normalmente, como complementos ou substitutos das etnografias que resultam em monografias escritas, seguindo algumas das convenções antropológicas convencionais - nomeadamente na procura de conhecer a diversidade cultural através de interlocutores representativos desta. Vejo precisamente aqui a matéria para que os diálogos entre antropólogos visuais e não visuais possam ser estimulados, num desafio que não é novo mas que se afigura tão necessário como reinventável nas formas e nas intensidades cooperativas ou colaborativas. Isto é, o audiovisual antropológico não é nem pode ser, por um lado, uma espécie de sucedâneo dos produtos textuais (são, de facto, outras coisas o que se procura conhecer e o que se consegue conhecer), nem, por oposição extrema, poderá cair num registo que não respeite quesitos antropológicos mínimos. Durington e Ruby identificam esta dificuldade:

"We look forward to future productions from those that have moved on into academic posts; many graduates of these training programs, however, have ended up with careers in the media and not as academic anthropologists. If the purpose of the training is to produce anthropologists who can make films as an expression of their scholarly work, then these programs are not working" (2011: 206).

Reconhecendo que esta conclusão não é partilhada por todos e que está sujeita a crítica forte, nomeadamente dos antropólogos que sustentam uma prática antropológica que não se esgota nas academias (e.g. Pink 2011), a verdade é que muitos alunos (antropólogos mas não só) se inscrevem em 
programas de filme etnográfico não para seguir antropologia mas para seguir carreiras mais ligadas ao cinema, à televisão e, em particular, à produção independente de filme documentário. É este o percurso de Catarina Alves Costa, ex-aluna do GCVA de Manchester, cujas produções têm derivado mais (mas não só) para circuitos não académicos. Todavia, o exemplo de Catarina Alves Costa parece-me apropriado por várias razões. Primeiro, porque foi ela que estabeleceu em Portugal, no início dos anos 90, um novo tipo de "cinema do real", estimulando relações entre televisão (mais do que cinema) e antropologia; em segundo lugar, porque continua a lecionar nos cursos de antropologia nas principais universidades portuguesas, transmitindo saberes interdisciplinares que devem muito a gramáticas extra-académicas (do cinema, da televisão, das artes plásticas) $;{ }^{10}$ e porque os seus filmes, inicialmente produzidos e difundidos em circuitos extra-académicos, acabam por "regressar" à academia através das aulas de antropologia visual por ela ou por outros ministradas.

De facto, não é a antropologia visual que está em causa enquanto disciplina por direito próprio (Banks e Ruby 201 l; Ruby 2005; Ribeiro 2004). O que aqui se discute é o uso das imagens e sua influência nos processos de produção de conhecimento e criação de representação pelos antropólogos, afirmando que são necessários usos mais regulares e profícuos que se traduzam em inovações metodológicas e novas reflexões teóricas, que, a meu ver, estão ainda muito deficitárias na antropologia. Apetece, pois, retomando o desafio fundador de Mead (1975), reafirmar que as imagens podem trazer novas possibilidades e oportunidades aos antropólogos nos seus processos de conhecimento (etnografia como processo) e representação do "outro" (etnografia como produto). Esta é, aliás, uma das obsessões de David MacDougall (1997), quando fala numa antropologia visual que se afirme como verdadeira alternativa à antropologia não visual, situando uma nova epistemologia do conhecimento/representação na convocação de novas combinações sensoriais. E se os interesses de Mead (1975) já não serão tão entusiasticamente abraçados nos dias de hoje, em particular a sua ingénua pretensão de cientificidade/objetividade no registo para efeitos arquivísticos e taxionómicos, não podemos negar o facto de que, passados 35 anos de afirmação e consolidação (Ruby 2005), a antropologia visual está ainda restrita a um universo de especialistas (antropólogos visuais, realizadores profissionais, fotógrafos) sem que se reconheça um envolvimento maior da parte da comunidade mais vasta de antropólogos.

Em 1975 Mead fazia um apelo "desesperado" ao uso dos meios visuais, alegando que o eventual desconhecimento das técnicas e o receio de as utilizar

10 Atualmente, existem formações fundadas nesta base interdisciplinar; por exemplo, a Pós-Graduação em Culturas Visuais Digitais no ISCTE-IUL, que “mistura”, entre outros conteúdos, antropologia, artes plásticas e webdesign. Ver < http://www.iscte-iul.pt/cursos/pos_graduacoes/12108/apresentacao. aspx $>$ (consultado a 30/4/2013). 
mal por parte dos seus colegas antropólogos seria uma não questão. Afinal, a antropologia, em particular com o impulso para o estudo da diversidade em contexto (Griffiths 2002), sempre acompanhou as inovações técnico-tecnológicas, delas fazendo uso, e não só ao nível do filme e da imagem mais em geral. Brady (1999) faz referência à forma como o fonógrafo veio alterar a etnografia no final do século XIX. Em meados dos anos 50 do século passado, a sincronização do som com a imagem gravada veio também produzir alterações substanciais no modo como os filmes etnográficos eram feitos até então - possibilitando, desde logo, uma nova relação cinematográfica e antropológica ao "dar voz" aos sujeitos filmados. Libertavam-se (ainda) mais as subjetividades que há muito alguns antropólogos procuravam; entre eles estava Jean Rouch, considerado fundador de um novo filme etnográfico que progressivamente fazia reconhecer a relação e as interações entre observados e observador nos processos de pesquisar antropologicamente.

Hoje em dia, as técnicas estão mais fáceis e disponíveis para todos (Campos 2011 ), assim como acontece com cursos e colaborações de outros profissionais que poderão complementar o trabalho dos antropólogos menos habilitados tecnicamente (Zoettl 2011). Será então pela natureza individualizada do trabalho do antropólogo e pela recusa de autorias partilhadas, com eco na elaboração dos textos, que as imagens não são utilizadas? O olho singular do antropólogo do terreno deverá ser escrutinado apenas pela sua especificidade relacional, interativa, dialógica, recusando contaminações colaterais de outros observadores etic? Ou será por razão eticometodológica, para não revelar identidades e preservar relações e interações sociais descobertas e descritas ao abrigo de confidencialidades negociadas, que reconhecemos um evitamento do uso das imagens?

Inerente a esta discussão é também a do (necessário) reconhecimento dos produtos audiovisuais para efeitos de currículo académico e a sua equalização estatutária relativamente aos textos científicos escritos (Crawford 2010). Nos últimos anos a questão tem sido debatida em fóruns de discussão como a Visual Anthropology Network of the European Association of Social Anthropologists (VANEASA) ou a Society for Visual Anthropology (SVA, presentemente inscrita na American Anthropological Association), deixando antever algumas alterações significativas no estatuto de "menoridade" a que os trabalhos antropológicos com imagens têm sido votados. Como é referido pela SVA, os meios e produtos audiovisuais oferecem contributos específicos para a antropologia que devem ser reconhecidos do ponto de vista da valorização curricular dos profissionais e dos conteúdos resultantes das investigações levadas a efeito:

"Ethnographic visual media (specifically film, video, photography, and digital multimedia) play a significant role in the production and application of anthropological knowledge and form an integral part of the discipline's 
course offerings. Anthropologists involved in the production of visual works make valuable scholarly contributions to the discipline. In addition, anthropologists increasingly include visual media productions as part of their curricula vitae" (Society for Visual Anthropology 2001).

Neste espetro de parcas relações intradisciplinares, não são só os antropólogos visuais, salvo raras e pontuais exceções (e.g. Zoettl 201 1; Campos 2011 ; Ribeiro e Bairon 2007; Ribeiro 2004; Fradique 1997), ou todos aqueles que não sendo antropólogos produzem imagens de cariz ou utilização etnográfica, que não sentem a necessidade ou a vontade de comunicar algumas das suas ideias e reflexões com os seus colegas e, concomitantemente, abrirem mais o seu trabalho aos antropólogos não visuais. A prática de incluir artigos de antropologia visual nas principais revistas de ciências sociais não é comum em Portugal. Na verdade, não existindo revistas da especialidade neste país, seria expectável que artigos de antropologia visual pudessem estar mais presentes em revistas como a Etnográfica e a Análise Social. ${ }^{11}$ Em sentido contrário, a prática dos antropólogos não visuais de escreverem sobre produtos audiovisuais (filmes, fotografias, desenhos, etc.) não é também muito comum. $\mathrm{Na}$ revista Etnográfica encontramos talvez uma das únicas e honrosas exceções, protagonizada por Maria Cardeira da Silva (2003) numa referência a quatro filmes temáticos (turismo) com os quais a autora discute uma questão central na antropologia - a do relativismo cultural. As suas palavras deambulam entre referências teóricas a textos escritos e os planos vistos e revistos nas imagens editadas pelos realizadores, embora a autorreconhecida informalidade do escrito possa pressupor que falar sobre filmes não é a mesma coisa que falar sobre textos. ${ }^{12}$

Creio, portanto, que há possibilidades a explorar e diálogos a incentivar de modo a que a antropologia faça mais uso e recurso das imagens para produzir novos conhecimentos e novas representações sobre culturas, sociedades, grupos e indivíduos. Apesar de a democratização dos vários acessos às novas tecnologias ser um facto inegável (Campos 2011; Pink 2011), o âmbito do audiovisual mantém-se na sombra (embora menos) nos cursos e departamentos de antropologia em Portugal. Existem disciplinas e graduações a serem oferecidas, vontade e interesse por parte de docentes e alunos nos cursos, e experimentações metodológicas em certas unidades curriculares; no entanto, o

11 As revistas de antropologia visual no mundo não existem em grande número. Com arbitragem por pares, na área da antropologia existe a Visual Anthropology e a Visual Anthropology Review, embora revistas como a Visual Studies, a Visual Communication, a Visual Sociology e a Visual Sociology Review sejam igualmente espaços reconhecidos para publicação de produção no âmbito dos estudos visuais (Davey 2010).

12 Não discutindo a sua importância como suporte etnográfico, a autora enaltece o papel do filme para a promoção da antropologia (Cardeira da Silva 2003: 451). 
audiovisual vive numa margem epistemológica, ou, sobretudo, há uma vigilância epistémica permanente que sobre ele é mantida num universo dominado pelos textos escritos e pelas palavras. Mesmo o filme etnográfico ou o documentário (e este convivendo, cada vez mais, noutros centros considerados menos académicos) são votados a um estatuto de menoridade representacional e de produção de um conhecimento menos antropológico sobre o social e o cultural. ${ }^{13}$ Esta margem faz-nos olhar para um centro (mainstream) teórico-epistemológico que teima em manter o registo metodológico por técnicas de pesquisa convencionais na antropologia: a etnografia com base na observação participante - trabalho de campo, registo escrito de notas e inquirições e passagem posterior a texto (ensaio, artigo, livro, manual) -, sendo este depois utilizado na formulação do argumento de ensino e na metodologia de transmissão de saberes e avaliação de aquisição (apesar da progressiva "powerpointização" das aulas significar uma conversão ao poder da imagem). A resistência à utilização do audiovisual acaba por traduzir, assim, o desejo de manter a antropologia (e as ciências sociais, em geral) imune à contaminação pouco científica do mesmo.

Pode o audiovisual (apenas, sem escrita) ser válido como representação antropológica? $\mathrm{Na}$ igual medida de uma antropologia feita via texto? Pode o visual criar acessos alternativos às dimensões culturais, sociais e individuais sob estudo em projetos antropológicos, constituindo-se como ferramenta metodológica com a mesma validade que os métodos de inquirição convencionais? Será possível pensar numa utilização do visual em âmbito alargado (Pink 2007a e 2007b; Jablonko 1995), com projetos não académicos (inscritos em produções artísticas ou âmbitos de intervenção social), que conviva harmoniosamente com as convenções académicas ao nível da antropologia e das ciências sociais?

\section{CONDIÇÕES CONTEMPORÂNEAS DA PESQUISA AUDIOVISUAL: OPORTUNIDADES E AMEAÇAS}

$\mathrm{Na}$ verdade, o meu argumento reconhece a produção de análises e interpretações específicas e alternativas sobre a realidade social através da utilização das imagens, em formatos continuamente renovados (e.g. digital e multimédia), num contexto atual de audiovisualização crescente do mundo, que tem efeitos nas sociedades, nos indivíduos e na própria ciência antropológica. Por um lado, são as investigações antropológicas que dão uso mais profícuo e assíduo ao audiovisual fora do próprio domínio especializado da antropologia visual e da antropologia académica (Banks e Ruby 201 l; Campos 201 1, Pink 2007b).

13 Esses outros centros não são necessariamente antagónicos, inconciliáveis, ou alheios a diálogos com a antropologia. O exemplo maior vem dos festivais/encontros de cinema documental que vão proliferando por todo o país, concorrendo para novas ligações entre a antropologia e o cinema/artes. Mas também temos o exemplo dos museus. 
Por outro, em muitas sociedades, assistimos a uma mediatização e a uma espetacularização extrema de fenómenos sociais e individuais que tem como exemplos a "facebookização" das relações e interações sociais e o que chamaria o "sobretelevisionamento" dos detalhes quotidianos das vidas individuais e familiares. São tendências sociais (e audiovisuais) que têm cúmulos nos formatos televisivos do género Big Brother, através dos quais assistimos não só a uma sobre-exposição de indivíduos aparentemente normais, mas também à própria produção identitária individual e coletiva em processos mediatizados. Tudo isto é realizado perante audiências de milhões de espetadores, que, por sua vez, incorporam e alimentam o desejo da sua própria exibição pública mediatizada.

Estes fenómenos sociais são obviamente facilitados por uma democratização no acesso aos meios de produção audiovisual (máquinas de filmar e de fotografar, software, etc.) e não apenas nas sociedades ditas "ocidentais" ou modernizadas. De facto, assistimos a uma globalização da representação e do direito à autorrepresentação audiovisual (e.g. cinema indígena) com importantes consequências para o modo como a antropologia pode estudar estes fenómenos (Edwards 2011; Ginsburg 2011; Zoettl 2011). Ou seja, estamos perante fenómenos que presumem nos seus atos de conhecimento e (melhor) representação a utilização das imagens (e sons), não só devido a uma dimensão espetacular (estética e visualizável) dos mesmos, mas, sobretudo, porque os seus agentes, fruto de pertenças e socializações coletivas, se reconstroem na sua singularidade e diferença através destes processos circunstanciais, precários, instáveis e tendentes à sua individuação (Wieviorka 2010 [2008]), utilizando, em muitos casos, o audiovisual como suporte privilegiado para a sua reconstrução identitária ou para a afirmação dela (Edwards 201 l; Ginsburg 2011 ). Estamos, de facto, perante agentes sociais que requerem uma antropologia ao nível do indivíduo (Lahire 2005) e cujo acesso metodológico otimizado é o audiovisual. Voltamos aqui ao argumento de Farnell e à sua teorização em torno dos "discourses from the body" (2011: 151) e à ideia de uma antropologia reflexiva que mostra as interações de conhecimento em processo. De facto, um do contributos teóricos fundamentais do uso do audiovisual deriva, em grande medida, de uma inerência óbvia inscrita no trabalho com as imagens e que se reflete no que Farnell designa como a recusa "of the body as a static object" (201 l: 151). A autora utiliza a expressão "segunda revolução somática" para sugerir uma rutura epistemológica com os tipos de conhecimento produzidos através das formas ditas convencionais. Grimshaw (2005) fala de formas hápticas de conhecimento para aceder aos sujeitos de estudo, que são hoje mais visualizáveis por uma certa exigência teórica relacionada com a individualidade do sujeito no mundo contemporâneo (Wieviorka 2010 [2008]; Lahire 2005), que não pode mais ser visto apenas e só como representativo de um ou vários coletivos, mas que se afirma como experiência singular num quadro de dinâmicas relacionais e interativas em permanente mudança (Jackson 1989). 
Isto é algo que coincide em termos metodológicos com a câmara-ator de Jean Rouch, que nos anos 50 do século passado antecipou, em filme, teorizações que mais tarde apareceriam escritas em torno de questões como as de autoria partilhada e a de dar voz aos outros com reconhecimento da sua copresencialidade. Rouch começou a incluir o operador de câmara no enquadramento dos seus planos. Esta decisão não teve que ver apenas com uma opção estética e/ou política (ética também). Nessa câmara que também nos mostra antropólogos que perguntam coisas de certa forma a outras pessoas, revejo um "movimento" epistemológico (ético e político) fundamental com vista ao reconhecimento, porventura tardio, de que a antropologia é feita com pessoas e por pessoas e de que o trabalho de campo, apesar do tempo longo e da proximidade, não garante objetividade, ajudando, pelo contrário, a situar devidamente as diversas subjetividades que resultam dos múltiplos encontros que ocorrem no trabalho de campo. Penso que esta é, de facto, uma das grandes virtudes de trabalhar com o audiovisual.

Posto isto, importa dizer que as imagens podem ter diferentes tipos de produtores, estatutos, origens e fins; podem ser produzidas pelos próprios antropólogos ou por outros indivíduos, sujeitos ou não da pesquisa (contemporâneos ou não do investigador); podem ser fixas (fotografia, desenho e gravura), em movimento (filme, vídeo) ou combinar os dois tipos (formatos multimédia e digital), e ter diferentes suportes de registo (câmaras profissionais, telemóveis, videovigilância); podem também ser produzidas ou não por antropólogos em contextos de pesquisa e ter uma intencionalidade etnográfica ou antropológica (mais ou menos explícita); i.e. as imagens têm um potencial de "etnograficidade" que é atribuível numa relação específica de investigação, o que significa que qualquer uma pode servir para a análise ou a interpretação antropológica, independentemente do seu ato de produção original (Pink 200la e 200lb). Tal como qualquer documento escrito, as imagens são também analisáveis pela sua indexicalidade semântica, remetendo para um lado invisível que contextualiza o que se vê, o que também significa dizer que um eventual desinteresse pela produção audiovisual de ficção (seja ela de que tipo for) não faz sentido. Todas as imagens são produtos culturais e janelas de conhecimento sobre atos e formas de pensamento humano.

As imagens chegam-nos, portanto, nas mais variadas formas, e para cada uma as convenções e possibilidades de uso, técnicas e ações complementares associadas são necessariamente diferentes; ou seja, para mencionar apenas as mais comuns, filme e fotografia garantem-nos possibilidades representacionais e objetos de conhecimento diferentes que, não sendo comparáveis no tipo de abordagem que o investigador pretenda realizar, podem complementar-se (Edwards 201 1; Griffiths 2002). Isto é algo que temos também que considerar a respeito da digitalização massiva e massificada do audiovisual, e que tem como uma das suas consequências mais importantes, para além do acesso facilitado 
à sua utilização, um potencial de transformação e manipulação criativa (ética e epistemologicamente discutíveis) dos registos originais por via de ferramentas informáticas disponibilizadas a baixo custo e pelas baixas competências técnicas requeridas. É a própria dicotomia original entre fixo e em movimento que está em causa, uma vez que todos registos são potencialmente modificáveis - pela imputação de movimento ou, em sentido contrário, por um processo de fixação.

$\mathrm{Na}$ verdade, o facto de podermos editar e transformar (numa aceção muito larga) qualquer registo original gravado tem consequências muito importantes ao nível do que se pode mostrar, da autoria, dos consentimentos negociados e das próprias virtudes epistemológicas do audiovisual para a antropologia (AAVV 2008). De facto, estamos perante oportunidades mas, igualmente, perante riscos quando e se esquecermos quesitos básicos ao nível da inquirição antropológica; em especial, é fundamental não "atalhar", num trabalho de campo que deve captar com profundidade e integridade as pessoas, eventos, performances e, mesmo, elementos de cultura material; não podemos também, por outro lado, negligenciar no ato de apresentação (edição da informação) uma boa representação do que presenciámos, escutámos e conhecemos. No limite, o risco é o da própria negação científica do registo, reconhecendo, todavia, que através das imagens mostramos coisas diferentes.

\section{NOTAS FINAIS}

"The process of gathering anthropological knowledge is today a subject of research in itself; however, studies focusing on the exchanges between research, information technology and artistic creation (photography, film, sounds, multimedia, fine arts... etc.) are still marginal [...] The mechanisms of creation in audio-visual anthropology question the belief system which holds that images alone can provide an objective reproduction of reality. In the field of ethnographic film, for example, creative experimentation allows one to go beyond the limits of direct [observational] cinema which, despite its descriptive richness, can too often appear to miss some of the initial aims of rendering the anthropological depth of the situations being filmed. As the tools of creation and data interpretation are getting richer and the methodology of fieldwork is being transformed, new forms of narration are coming into being $[\ldots]]^{14}$

Será consensual o argumento de que as imagens trazem novos e bons contributos à antropologia em geral e não apenas à antropologia visual e que esta,

14 Nadine Wanono e Gilles Remillet, em EASA Workshop W012 “Contemporary hybrids in visual anthropology", em <http://www.nomadit.co.uk/easa/easa2012/panels.php5?PanelID=1269> (consultado a 30/4/2013). 
enquanto disciplina de contacto e proximidade, oferece à primeira contributos específicos para o seu projeto intelectual e disciplinar de conhecimento e reconhecimento da diversidade cultural, social e individual no mundo, ajudando-nos a conhecer e reconhecer outras coisas e de outras formas (Herzfeld 201 1; Grimshaw 2005; Okely 2001; MacDougall 1997). Será também irrefutável o imperativo de que a antropologia visual mantenha vínculos, sobretudo teóricos e metodológicos, com a antropologia social. Neste sentido, respondendo a uma antiga (mas pertinente) observação de Pina-Cabral (1983: 328), não só o vídeo não dispensa o "etnógrafo paciente de papel e caneta na mão", como exige a sua presença e competências de observação configuradas numa base antropológica. Em concreto, os pressupostos de um trabalho de campo com observação participante não podem ser negligenciados.

A questão, portanto, será sempre a de saber se o vídeo tem a mesma importância do "papel escrito pela caneta" - independentemente de o produtor das imagens ser ou não antropólogo (visual). Não está em causa quem faz, mas o que se faz e a sua receção pela antropologia, reivindicando-se mais e melhores diálogos entre antropólogos visuais e não visuais, mais encontros, aberturas de congressos com produtos audiovisuais - mais imagens, hapticismo e subjetivismo -, uma outra centralidade para o visual e para as imagens na antropologia, quiçá, como referi, não desejada pelos próprios antropólogos visuais, porque os melhores e mais regulares diálogos parecem ser feitos com as artes - cinema, fotografia, pintura - e pelo reconhecimento dos seus produtos nos campos das artes.

Como referi, as imagens acompanham a história da antropologia; estão na sua génese e no seu projeto de (re)conhecimento da diversidade cultural e social no mundo. Primeiro com gravuras e desenhos, depois com a fotografia e mais tarde com o filme. Os primórdios do trabalho de campo antropológico moderno coincidem com explorações metodológicas que utilizam imagens. A expedição da Universidade de Cambridge ao Estreito de Torres, liderada por Alfred Cort Haddon, não é apenas um marco na antropologia visual. Ali começa a ser feito um tipo de trabalho de campo que, mais tarde, Malinowski consolida. Haddon e W.H. Rivers anunciavam a mudança de uma ciência da natureza (física, biológica, taxionómica) para uma ciência humanista (acesso ao mundo a conhecer em primeira mão e ao ponto de vista nativo com conhecimento contextual).

Porventura, a realidade social encontrar-se-á melhor representada entre (ou conjuntamente por) produtos audiovisuais e textos escritos. Pois bem, que se multipliquem as presenças nos seminários, nos debates e nas mostras de filmes, produzidas para pesquisas antropológicas de antropólogos não visuais ou nelas utilizadas, e que as suas imagens sejam escrutinadas em artigos de antropologia social com mais frequência, recuperando a proposta sobre a "etnograficidade" das imagens depender das suas apropriações para fins de pesquisa (Pink 2001 a 
e 2001 b). É certo que existem áreas de especialização na antropologia (e.g. performance e urbana) que, por razão da disponibilidade visual dos seus objetos de estudo preferenciais, recorrem frequentemente às imagens como forma de investigar ou como produtos de investigação. No caso concreto dos estudos da performance, a inerente ligação às artes e ao conceito de espetáculo como ato público pressupõe a necessidade de ver (e ouvir) - presenciar -, o que torna praticamente indispensável a disponibilização de recursos imagético-sonoros aos seus leitores/espetadores. Por outro lado, importa também reconhecer que a antropologia visual (re)conquistou nos últimos anos notoriedade, verificável em indicadores como a oferta de formações de nível superior (pós-graduações), o aparecimento de unidades curriculares nos cursos de ciências sociais e, em particular, a produção relativamente significativa de filme documentário - neste caso, justificada também pela existência de formações em cinema e pela proliferação de festivais nacionais e internacionais.

Em suma, uma antropologia visual que seja feita em constante e renovado diálogo com a antropologia social, processo muito negligenciado apesar da sua progressiva e sustentada afirmação disciplinar no mundo (Banks e Ruby 2011 ; Davey 2010; Ruby 2005), não pode passar apenas por ver filmes ou fotografias como forma de ilustração das diferenças, dos exóticos mais ou menos distantes. Ver através das imagens e com imagens passa pelos atos de ver (to see) e não apenas olhar (to look at), que, por exemplo, Berger (2009) constantemente reclama. Será através desta forma de "tratar" (no duplo sentido de lidar com algo e de cuidar) as imagens que a antropologia pode beneficiar da sua utilização. Seguramente, como mostrou o meu trabalho (Martins 2005), poderemos criar perspetivas diferentes sobre a realidade social - sobre indivíduos, grupos, processos, performances - e, de certo modo, liquidificar a solidez de conclusões finais (sempre precárias à luz do reconhecimento da circunstancialidade histórica de cada observação e dos próprios "decisivos" imponderáveis da vida quotidiana, dos quais enquanto investigadores também fazemos parte). Neste processo, as imagens servirão para mostrar como todo o conhecimento pode ser então provisório e refundível (Edwards 2011), até porque, revelando indivíduos concretos (com um rosto, um corpo e uma voz), a emergência de subjetividades é exponenciada. Refiro-me à subjetividade como dizendo respeito não só ao sujeito conhecedor, mas, sobretudo, ao sujeito conhecido, que, cada vez mais, está atento às representações que sobre si são criadas, querendo também criar e ser dono da sua representação (Edwards 2011; Ginsburg 2011). Falamos, portanto, do audiovisual como garante de uma intersubjetividade alargada, de diálogo e verificação emic-etic, no sentido em que ambos (sujeito observador e sujeito observado) se (re)veem nos atos de inquirição (relação e interação), numa espécie de democratização do conhecimento que tem vínculo numa antropologia (visual) partilhada que tem em Rouch e no casal MacDougall alguns dos protagonistas principais. 


\section{BIBLIOGRAFIA}

AAVV, 2008, "Visual ethics: ethical issues in visual research", ESRC National Centre for Research Methods Review Paper, Working Paper Series, 1 1/08.

ASCH, Timothy, John MARSHALL, e Peter SPIER, 1973, "Ethnographic film: structure and function”, Annual Review of Anthropology, 2: 179-187.

BANKS, Marcus, e Jay RUBY, 2011, "Made to be seen: historical perspectives on visual anthropology", em Marcus Banks e Jay Ruby (orgs.), Made to Be Seen: Perspectives on the History of Visual Anthropology. Chicago e Londres, The University of Chicago Press, 1-18. BERGER, John, 2009, Why Look at Animals? Londres e Nova Iorque, Penguin Books.

BRADY, Erika, 1999, A Spiral Way: How the Phonograph Changed Ethnography. Jackson, MS, University Press of Mississippi.

BRITO, Joaquim Pais de, 1996, Retrato de Aldeia com Espelho: Ensaio sobre Rio de Onor. Lisboa, Dom Quixote.

CAMPOS, Ricardo, 2011, "Imagem e tecnologias visuais em pesquisa social: tendências e desafios”, Análise Social, XLVI (199): 237-259.

CORNU, Tanguy, 2010, "La photographie comme révélateur d'un terrain: les cas des meetings de tunning”, ethnographiques.org, 21, disponível em <http://www.ethnographiques. org/2010/Cornu > (consultado a 30/4/2013).

CRAWFORD, Peter, 2010, "Recognition of audio-visual products/publications: a brief report”, NAFA Network, 17 (5): 22-25.

DAVEY, Gareth, 2010, "Visual anthropology: strengths, weaknesses, opportunities and threats", Visual Anthropology, 23: 344-352.

DURINGTON, Matthew, e Jay RUBY, 2011 , "Ethnographic film”, em Marcus Banks e Jay Ruby (orgs.), Made to Be Seen: Perspectives on the History of Visual Anthropology. Chicago e Londres, The University of Chicago Press, 190-208.

EDWARDS, Elisabeth, 2011 , “Tracing photography”, em Marcus Banks e Jay Ruby (orgs.), Made to Be Seen: Perspectives on the History of Visual Anthropology. Chicago e Londres, The University of Chicago Press, 159-189.

FABIAN, Johannes, 1983, Time and the Other: How Anthropology Makes Its Object. Nova Iorque, Columbia University Press.

FARNELL, Brenda, 201 1, “Theorizing 'the body' in visual culture”, em Marcus Banks e Jay Ruby (orgs.), Made to Be Seen: Perspectives on the History of Visual Anthropology. Chicago e Londres, The University of Chicago Press, 136-158.

FRADIQUE, Teresa, 1997, "A Senhora e o rio: dois novos olhares do documentarismo em Portugal”, Etnográfica, I (2): 339-345.

GINSBURG, Faye, 2011, "Native intelligence: a short history of debates on indigenous media and ethnographic film", em Marcus Banks e Jay Ruby (orgs.), Made to Be Seen: Perspectives on the History of Visual Anthropology. Chicago e Londres, The University of Chicago Press, 234-255.

GRAY, Gordon, 2010, Cinema: A Visual Anthropology. Oxford e Nova Iorque, Berg.

GRIFFITHS, Alison, 2002, Wondrous Difference: Cinema, Anthropology and Turn-of-the-Century Visual Culture. Nova Iorque, Columbia University Press.

GRIMSHAW, Anna, 1997, "The eye in the door: anthropology, film and the exploration of interior space”, em Howard Morphy e Marcus Banks (orgs.), Rethinking Visual Anthropology. New Haven e Londres, Yale University Press, 36-52. 
GRIMSHAW, Anna, 2001 a, “Teaching visual anthropology: notes from the field”, Ethnos, 66 (2): 237-258.

GRIMSHAW, Anna, 2001b, The Ethnographer's Eye: Ways of Seeing in Anthropology. Cambridge, Cambridge University Press.

GRIMSHAW, Anna, 2005, "Eyeing the field: new horizons for visual anthropology", em A. Grimshaw e A. Ravetz (orgs.), Visualizing Anthropology. Bristol e Portland, Intellect, 17-30.

GRIMSHAW, Anna, e Amanda RAVETZ (orgs.), 2005, Visualizing Anthropology. Bristol e Portland, Intellect.

HAMMOND, Joyce, 1998, "Photography and the 'natives': examining the hidden curriculum of photographs in introductory anthropology texts”, Visual Studies, 13 (2): 57-73.

HENLEY, Paul, 2004; "Seeing, hearing, feeling: sound and the despotism of the eye in 'visual' anthropology", apresentado no workshop "I saperi dello sguardo", Siena, Universidade de Siena.

HERZFELD, Michael, 201 1, "Ethical and epistemic reflections on/of anthropological vision", em Marcus Banks e Jay Ruby (orgs.), Made to Be Seen: Perspectives on the History of Visual Anthropology. Chicago e Londres, The University of Chicago Press, 313-333.

HOCKINGS, Paul (org.), 1975, Principles of Visual Anthropology. Haia e Paris, Mouton Publishers.

JABLONKO, Allison, 1995, "Structuring visual materials", Visual Anthropology, 7: 283-296.

JACKSON, Michael, 1989, Paths Toward a Clearing: Radical Empiricism and Ethnographic Inquiry, Bloomington e Indianapolis, Indiana University Press.

LAHIRE, Bernard, 2005, "Patrimónios individuais de disposições: para uma sociologia à escala individual”, Sociologia, Problemas e Práticas, 49: 11-42.

LEE, Jo, e Tim INGOLD, 2006, "Fieldwork on foot: perceiving, routing, socializing", em Simon M. Coleman e Peter Collins (orgs.), Locating the Field. Space, Place and Context in Anthropology, Oxford, Berg, 67-86.

MacDOUGALL, David, 1995, "The subjective voice in ethnographic film", em Leslie Devereux e Roger Hillman (orgs.), Fields of Vision. Berkeley, University of California Press, 217-255.

MacDOUGALL, David, 1997, "The visual in anthropology”, em Marcus Banks e Howard Morphy (orgs.), Rethinking Visual Anthropology. New Haven e Londres, Yale University Press, 276-295.

MARTINS, Humberto, 2005, Will the Rocks Crumble One Day? Past and Present in the Portuguese Galician Frontier: Border Relations and Memories, Manchester, University of Manchester, tese de doutoramento (com DVD).

MARTINS, Humberto, 2011 , "Etnografias visuais: (im)possibilidades de uma antropologia visual aplicada”, em José Portela, Pedro Silva e Octávio Sacramento (orgs.), Etnografia e Intervenção Social: Por Uma Praxis Reflexiva. Lisboa, Colibri, 85-109.

MEAD, Margaret, 1975, "Visual anthropology in a discipline of words", em Paul Hockings (org.), Principles of Visual Anthropology. Haia e Paris, Mouton Publishers, 3-10.

MORIÉS, Branca, e Clara SARAIVA, 2010, “Trabalhos e registos”, Etnográfica, 14 (1): 177-184. MORTON, Christopher, 2005, "The anthropologist as photographer: reading the monograph and reading the archive”, Visual Anthropology, 18 (4): 389-405.

OKELY, Judith, 2001, "Visualism and landscape: looking and seeing in Normandy", Ethnos, 66 (1): 99-120. 
PINA-CABRAL, João de, 1983, "Notas críticas sobre a observação participante no contexto da etnografia portuguesa”, Análise Social, XIX (76): 327-339.

PINK, Sarah, 2001 a, Doing Visual Ethnography: Images, Media and Representation in Research. Londres, Sage.

PINK, Sarah, $200 \mathrm{lb}$, "More visualising, more methodologies: on video, reflexivity and qualitative research", Sociological Review, 49 (4): 586-599.

PINK, Sarah, 2006, The Future of Visual Anthropology: Engaging the Senses. Oxon e Nova Iorque, Routledge.

PINK, Sarah, 2007a, "Walking with video", Visual Studies, 22 (3): 240-252.

PINK, Sarah (org.), 2007b, Visual Interventions: Applied Visual Anthropology. Oxford e Nova Iorque, Berghahn Books.

PINK, Sarah, 2011, "Doing visual anthropology", em Marcus Banks e Jay Ruby (orgs.), Made to Be Seen: Perspectives on the History of Visual Anthropology. Chicago e Londres, The University of Chicago Press, 209-233.

PINTO, José Madureira 2010, "Breves notas sobre a pesquisa sociológica de terreno com câmara”, em José Madureira Pinto e João Queirós (orgs.), Ir e Voltar: Sociologia de Uma Colectividade Local do Noroeste Português (1977-2007). Porto, Edições Afrontamento, 96-102.

RIBEIRO, José, 2004, Antropologia Visual: Da Minúcia do Olhar ao Olhar Distanciado. Porto, Edições Afrontamento.

RIBEIRO, J., e S. BAIRON (orgs.), 2007, Antropologia Visual e Hipermedia. Porto, Edições Afrontamento.

ROUCH, Jean, 1975, “The camera and man”, em Paul Hockings (org.), Principles of Visual Anthropology. Haia e Paris, Mouton Publishers, 83-102.

ROUCH, Jean, 1995, “Os pais fundadores: dos antepassados totémicos aos investigadores de amanhã”, em AAVV, Imagens do Mundo: Mostra de Cinema Etnográfico Francês. Lisboa, CEAS, CEMRI e Serviço Cultural da Embaixada Francesa, 11-18.

RUBY, Jay, 2005, “The last 20 years of visual anthropology: a critical review”, Visual Studies, 20: 159-170.

SCHNEIDER, Arnd, 2011, "Unfinished dialogues: notes toward an altenative history of art and anthropology", em Marcus Banks e Jay Ruby (orgs.), Made to Be Seen: Perspectives on the History of Visual Anthropology. Chicago e Londres, The University of Chicago Press, 108-135.

SILVA, Maria Cardeira da, 2003, "Video tours", Etnográfica, VII (2): 451-458.

SOCIETY FOR VISUAL ANTHROPOLOGY, 2001, "Guidelines for the evaluation of ethnographic visual media (AAA statement)”, disponível em < http://www.aaanet.org/about/Policies/Guide_Visual.cfm > (consultado a 30/4/2013).

STOLler, Paul, 1992, The Cinematic Griot: The Ethnography of Jean Rouch. Chicago e Londres, The University of Chicago Press.

TEMANER, Gerald, e Gordon QUINN, 1975, "Cinematic social inquiry”, em Paul Hockings (org.), Principles of Visual Anthropology. Haia e Paris, Mouton Publishers, 53-64.

WIEVIORKA, Michel, 2010 [2008], Nove Lições de Sociologia: Como Abordar Um Mundo em Mudança? Lisboa, Teorema.

WOLBERT, Barbara, 2000, "The anthropologist as photographer: the visual construction of ethnographic authority”, Visual Anthropology, 13 (4): 321-343.

ZOETTL, Peter Anton, 2011 , "Aprender cinema, aprender antropologia", Etnográfica, 15 (1): 185-191. 


\section{FILMOGRAFIA E MULTIMÉDIA}

ASCH, Timothy, e Napoleon CHAGNON, 1975, The Ax Fight, Documentary Educational Resources, 30’.

GUimarães, Regina, e SAGUENAIL, 2008, O Compasso, Instituto de Sociologia - FLUP, 150'.

MARTINS, Humberto, 2003, Fazendo (o) Tempo, GCVA, 62'.

MEAD, Margaret, e Gregory BATESON, 1951, A Balinese Family, University of North Carolina Library e Penn State Media, 20'. 